\title{
Papers
}

\section{Impact of upward social mobility on population mortality: analysis with routine data}

\author{
Richard F Heller, Patrick McElduff, Richard Edwards
}

\begin{abstract}
Objective To examine the contribution of changes in the distribution of social class to the mortality of the whole population between 1970-2 and 1991-3. Design Examination of routine data at two time points: 1970-2 and 1991-3.

Data source Data provided by the Office for National Statistics.

Main outcome measures Difference for the total population in the number of deaths between 1971 and 1991. Proportion of difference accounted for by change in population size, change in risk of death within each social class, or change in distribution of population across social classes.

Results Reductions in mortality between 1970-2 and 1991-3 among men in England and Wales were partially (16\% of all deaths) attributable to increases in the proportion of men in higher social classes, representing 3943 fewer deaths per year or one less death for every 3056 men in 1991-3 compared with 1970-2.

Conclusion Some of the observed reduction in mortality seen between 1970-2 and 1991-3 can be accounted for by improved overall socioeconomic status of the population.
\end{abstract}

\section{Introduction}

The impact of socioeconomic status on health outcomes has been well documented for many years. In 1845 Engels reported the impact of housing on mortality from a population perspective. ${ }^{1}$ In recent years the topic of health inequality has developed increasing social and political importance, and one of the spurs to this has been the demonstration of a large and widening gap in death rates between the extremes of the social distribution. ${ }^{2-5}$ However, this may give a distorted view of the overall level of health inequality due to social class differentials as it does not take into account the changing distribution of social class within the whole population.

Between 1970-2 and 1991-3 mortality in the higher and lower social classes diverged in England and Wales, but there was also a reduction in the proportion of people in the lower social classes. Various methods for assessing the overall contribution of socioeconomic differentials to population mortality have been proposed, but there is no agreement about the best single measure. ${ }^{6}$

We approached the problem from a different perspective and assessed the potential impact of changes in the composition of social class on population mortality. To do so, we measured the contribution of changes in the risk of death within social classes and changes in the distribution of the population between social classes to the change in total deaths between 1970-2 and 1991-3.

\section{Methods}

The data for this analysis were provided by the Office for National Statistics and were analysed only for men aged 25-64 years. We used men because classification by occupation is much more valid in men than in women as married women are classified by the occupation of their husband. Social class, defined by the registrar general's classification of occupations, is usually presented as six individual groups: I-professional, II-managerial and technical/ intermediate, IIIa-skilled non-manual, IIIb-skilled manual, IV-partly skilled, and V-unskilled. We combined groups IIIa and IIIb to simplify the results.

We calculated the average annual all cause mortality for England and Wales separately for 1970-2 and 1991-3. For each period and within each 10 year age and social class grouping we calculated the all cause mortality by dividing the average number of deaths per year by the total population in that group. We used the census estimates for 1971 and 1991 as population denominators for these periods.

Within each age group we calculated the difference (d) in the number of deaths between 1971 and 1991. We then partitioned the difference as being due to the change in the size of the population $\left(\mathrm{d}_{1}\right)$; the change in the risk of death within each social class $\left(d_{2}\right)$; or the change in the distribution of the population across social classes $\left(d_{3}\right)$.

\section{Partitioning change}

Firstly, for each social class and age group we created a 1971 adjusted population with the same social class structure and rate of death as the observed $1971 \mathrm{popu}-$ lation but with the population size seen in 1991. This removed the increase or decrease in the number of deaths $\left(d_{1}\right)$ resulting from a change in the size of the population.
Evidence for
Population Health
Unit, School of
Epidemiology and
Health Sciences,
Medical School,
University of
Manchester,
Manchester
M13 9PT
Richard F Heller
professor of public
health
Patrick McElduff
lecturer in medical
statistics
Richard Edwards
senior lecturer in
public health
Correspondence to:
R F Heller
Dick.Heller@
man.ac.uk
bmj.com 2002;325:134 
We then applied the 1991 mortality to the 1971 adjusted population. The difference $\left(\mathrm{d}_{2}\right)$ between the number of deaths in the 1971 adjusted data and the number of deaths calculated when the 1991 mortality was applied to the 1971 adjusted population is the reduction in the number of deaths that occurred because of the reduction in the risk of death within each social class. The difference $\left(d_{3}\right)$ between the observed number of deaths in the 1991 population and the number of deaths when the 1991 mortality was applied to the 1971 adjusted population is the reduction in the number of deaths due to the redistribution of people within social classes.

\section{Results}

Within each social class the risk of death declined over the study period, but the decline was slower in social class V (fig 1). However, there was a substantial shift in the distribution of the population between social classes (fig 2). In particular the proportion of men in social class II increased from $19.9 \%$ to $30.3 \%$ (table 1 ). This was offset by reductions in the proportion of the population in social classes III, IV, and V.

Table 2 uses the age group 45-54 years to demonstrate the method used for partitioning the reduction in deaths between 1970-2 and 1991-3. There were
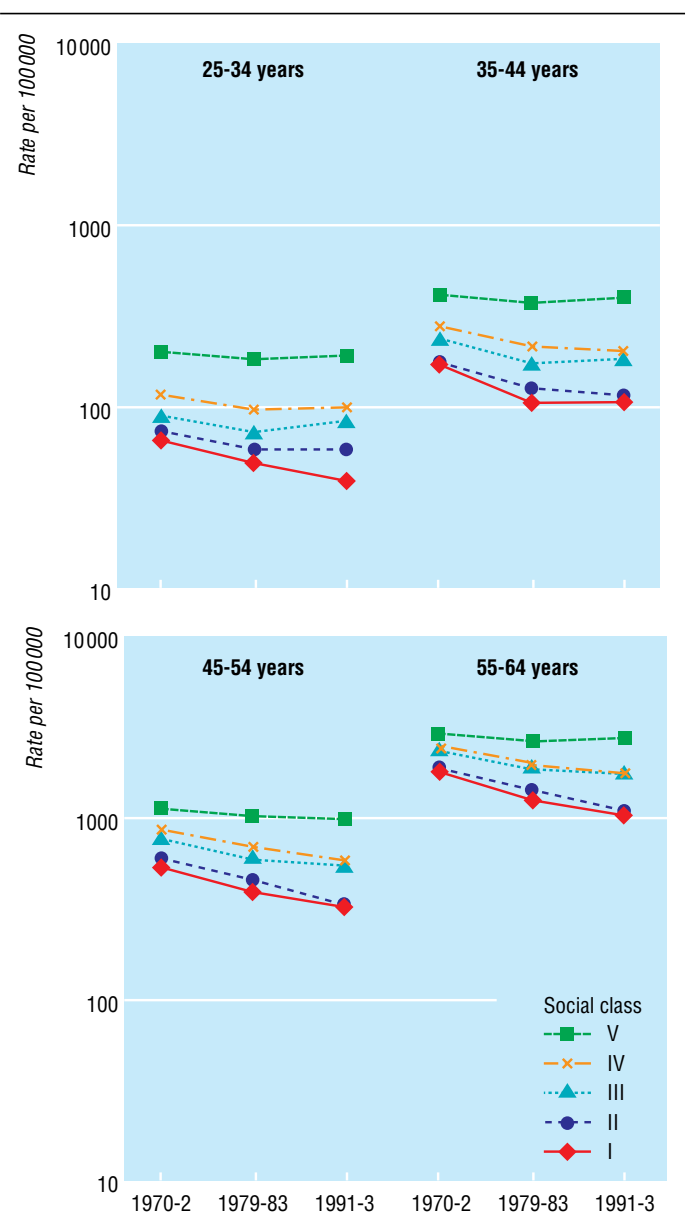

Fig 1 Trends in average rate of death from all causes for men from 1970-2 to 1991-3 for each 10 year age group
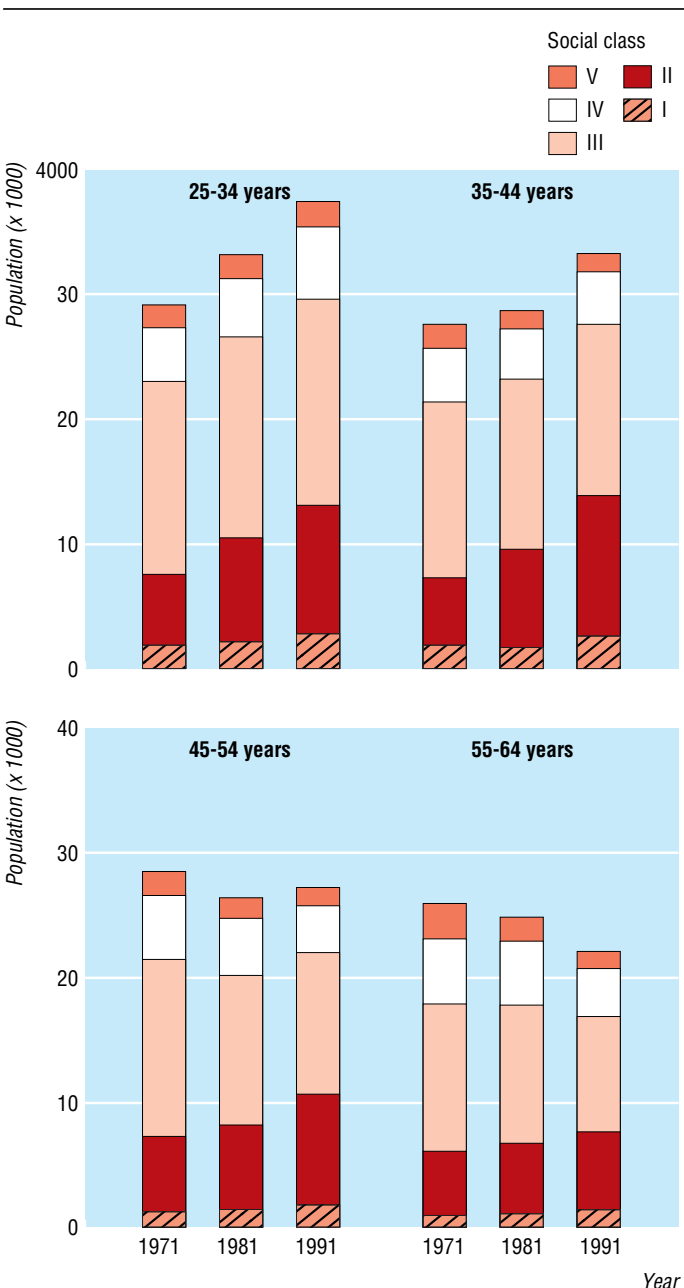

Fig 2 Trends in population distribution across social classes from 1971 to 1991 for men in each 10 year age group from 25 to 64 years

8384 fewer deaths in 1991-3 than in 1970-2 (20 $740-12356)$. From 1971 to 1991 the population fell by $5.1 \%$ from 2.87 million to 2.72 million. If we apply the 1971 death rates to the 1991 population size we get $1052(20740-19688)$ fewer deaths per year. The difference $\left(\mathrm{d}_{2}\right)$ between the number of deaths in the 1971 adjusted population and the number of deaths when the 1991 death rates are applied to the 1971 adjusted population is 6290 (19 688-13 398). This represents the reduction in the number of deaths attributable to the reduced risk of death within each social class. The difference between the number of deaths when the 1991 death rates are applied to the 1971 adjusted population and the number of deaths observed in 1991 is $1042(13398-12$ 356). This is the

Table 1 Percentage of men aged 25-64 years in each social class in 1971, 1981, and 1991

\begin{tabular}{lrrr} 
& \multicolumn{3}{c}{ Year } \\
\cline { 2 - 4 } Social class & $\mathbf{1 9 7 1}$ & $\mathbf{1 9 8 1}$ & $\mathbf{1 9 9 1}$ \\
\hline I & 5.6 & 6.3 & 7.5 \\
\hline II & 19.9 & 24.7 & 30.3 \\
\hline III & 49.7 & 46.8 & 42.5 \\
\hline IV & 17.4 & 16.4 & 14.7 \\
\hline V & 7.4 & 5.8 & 5.0 \\
\hline
\end{tabular}


Table 2 Example of methods used to determine reasons for reduction in number of deaths, ${ }^{*}$ using death rates per 1000 in men aged 45-54 years

\begin{tabular}{|c|c|c|c|c|c|c|}
\hline \multirow[b]{2}{*}{$\begin{array}{l}\text { Social } \\
\text { class }\end{array}$} & \multicolumn{4}{|c|}{ Observed } & \multicolumn{2}{|c|}{ Expected (No of deaths†/adjusted 1971 population‡) } \\
\hline & $\begin{array}{l}\text { Average No of deaths in } \\
1970-2 / \text { population in } 1971\end{array}$ & Death rate & $\begin{array}{l}\text { Average No of deaths in } \\
1991-3 / \text { population in } 1991\end{array}$ & Death rate & $\begin{array}{l}\text { Based on observed rate of } \\
\text { death in } 1971\end{array}$ & $\begin{array}{c}\text { Based on observed rate of } \\
\text { death in } 1991\end{array}$ \\
\hline I & $693 / 137280$ & 5.0 & $596 / 195002$ & 3.1 & $658 / 130319$ & $398 / 130319$ \\
\hline II & $3433 / 610211$ & 5.6 & $2759 / 879726$ & 3.1 & $3259 / 579267$ & $1816 / 579267$ \\
\hline III & $10202 / 1400277$ & 7.3 & $5751 / 1138635$ & 5.1 & $9684 / 1329270$ & $6714 / 1329270$ \\
\hline IV & $4181 / 512204$ & 8.2 & 2 092/383 937 & 5.4 & $3969 / 486230$ & $2649 / 486230$ \\
\hline V & 2 231/209 293 & 10.7 & $1159 / 126466$ & 9.2 & $2118 / 198680$ & $1820 / 198680$ \\
\hline Total & $20740 / 2869265$ & & $12356 / 2723766$ & & $19688 / 2723766$ & 13 398/2 723766 \\
\hline
\end{tabular}

*Formula for method (see text):

Total $(\mathrm{d})=20740-12356=8384$

Reduction in population size $\left(d_{1}\right)=20740-19688=1052$

Lower risk of death $\left(d_{2}\right)=19688-13 \quad 398=6290$

Social class redistribution $\left(d_{3}\right)=13$ 398-12 356=1042.

†Expected number of deaths calculated by applying observed death rate for period to adjusted 1971 population.

$\ddagger$ Age specific population in 1971 is adjusted to account for change in size of population between 1971 and 1991.

reduction in deaths attributable to the change in the distribution of social class across the population $\left(\mathrm{d}_{3}\right)$. Thus, if we exclude the number of deaths attributable to a change in the size of the population, $14 \%$ $(1042 /(1042+6290))$ of the reduction in deaths in this age group between 1971 and 1991 was due to a shift in the population distribution from lower to higher social class.

Table 3 presents the results separately for each 10 year age group from 25 to 64 years and the combined results for men aged 25-64 years. After we excluded changes in deaths attributable to changes in the population size, the number of deaths among men aged 25-64 years fell by 32\% between 1970-2 and 1991-3. Most of the reduction was due to the reduction in the risk of death within each social class but $16 \%$ of the reduction resulted from social class redistributionmovement in the population from lower to higher social class. Overall there were 3943 fewer deaths per year in 1991-3 due to the effects of social class than in 1970-2. The total population of men aged 25-64 years in 1991-3 for whom the social class distribution is known was 12049 803. Thus the upward movement in social class between 1970-2 and 1991-3 resulted in one fewer death per year for every 3056 men in the 1991-3 population.

\section{Discussion}

\section{The population impact}

We have shown that changes in the distribution of social class across the population are an important contributor to recent reductions in mortality and may be responsible for $16 \%$ of the reduction in mortality between 1970-2 and 1991-3. This is due to a decrease in the proportion of the population at the lower end of the social distribution associated with movement up the social scale, mainly a large increase in the proportion of the population in social class II. Expressed in absolute numbers (consistent with the population impact number ${ }^{7}$ ) we found that there was one fewer death per year for every 3056 men in 1991-3 attributable to the impact of social class redistribution between 1970-2 and 1991-3.

We have used a simple and pragmatic method to identify the specific contribution of changes in social class distribution to changes in the numbers of deaths in the population and hence estimate the population impact of this redistribution. The method takes into account not only the risk associated with individual social class groups but also the distribution of social class across the whole population. We have described elsewhere the importance of developing methods to examine and present the population impact of various risks and interventions. ${ }^{78}$

\section{Health inequalities}

There have been many recent papers and reports describing an increase in health inequalities in the United Kingdom..$^{2-5}$ Although some of these reports have noted the improvement in overall mortality over time, most assessed the level of inequality within the population based only on the widening gap between those at the extremes of the socioeconomic distribution. This has generally been expressed as the relative mortality difference between higher and lower social classes or between the least and most deprived areas.

Table 3 Number of deaths in each age group and number of deaths prevented in 1991-3 as result of changes in risk and changes in social class distribution between 1970-2 and 1991-3

\begin{tabular}{|c|c|c|c|c|c|}
\hline & \multicolumn{5}{|c|}{ Age group (years) } \\
\hline & $25-34$ & $35-44$ & $45-54$ & $55-64$ & $25-64$ \\
\hline \multicolumn{6}{|l|}{ Average annual No of deaths in each period: } \\
\hline $1970-2$ & 2768 & 6292 & 20740 & 55561 & 85361 \\
\hline $1991-3$ & 3011 & 5279 & 12356 & 32379 & 53025 \\
\hline Change in No of deaths between $1970-2$ and $1991-3$ & +242 & -1013 & -8384 & -23182 & -32336 \\
\hline $\begin{array}{l}\text { Change in No of deaths due to change in size of population 1970-2 to } \\
1991-3\left[d_{1}\right]\end{array}$ & +779 & +1261 & -1052 & -7917 & -6929 \\
\hline $\begin{array}{l}\text { Real reduction in No of deaths (excluding reduction due to changes in } \\
\text { population size) }\left[d_{2}+d_{3}\right]\end{array}$ & 537 & 2274 & 7332 & 15265 & 25407 \\
\hline $\begin{array}{l}\text { Reduction due to social class redistribution }\left[\mathrm{d}_{3}\right] \text { (No (\%) of real reduction in } \\
\text { deaths) }\end{array}$ & $117(22)$ & $536(24)$ & $1042(14)$ & $2249(15)$ & $3943(16)$ \\
\hline
\end{tabular}


Our method shows that the slower reduction in all cause mortality among men in social class $\mathrm{V}$ compared with men in other social classes does not necessarily imply that there has been a widening in overall inequality in health, once redistribution between the social classes is taken into account. Mackenbach and Kunst reviewed various measures for assessing overall health inequality within a population and concluded that there was no single best approach. ${ }^{6}$ Our method does not address this issue directly, but it does allow the relative contribution of changes in social class distribution and reductions in mortality within social classes to be described.

One criticism of the method is that it assumes that all members of a social class have the same risk of death and that movement between social classes is followed by adoption of the mortality profile of the new social class. This is unlikely to be true, particularly in the short term. However, the method of assessing levels of health inequality based on the widening of relative mortality between the highest and lowest social classes may also be flawed as the change may partly be an artefact of health selection. For example, men who were in social class V in 1971 and remained so in 1991 may be a selected group who are less healthy and hence have a higher mortality than those who ascended the social scale between 1971 and 1991. Similarly, illness may result in a shift down the social class distribution. The effect of this would be to produce an apparent increase in death rates in social class V. Mortality of those who are socially mobile has been shown to lie between those of the classes they leave and join. ${ }^{9}$ However, we acknowledge that the impact of these effects may be modest ${ }^{10}$ and that there is evidence of widening inequalities between affluent and deprived populations that probably are not due to such selection effects. ${ }^{11}$

\section{Policy relevance}

Current health policy focuses on reducing the gap between the lower social classes or areas with the worst mortality and the population as a whole-for example, as in the national health inequalities targets. ${ }^{12} \mathrm{We}$ believe that reducing mortality differentials between the lower end of the socioeconomic distribution and the average should not be the only focus of health policy as it is only one component of the population impact of socioeconomic differentials in health. Such an approach ignores a powerful mechanism for improving the health of those from the lowest socioeconomic groups by shifting the distribution of socioeconomic status upwards within the population. Rose and Day showed that a shift in the population mean was the most powerful stimulant to change at the extremes of the distribution. ${ }^{13}{ }^{14}$ This message has been lost in the focus on improving health of high risk groups at the lower end of the social distribution.

We should certainly not ignore efforts to improve the health of those at greatest disadvantage. However, our findings show that this should be combined with a policy to improve the overall socioeconomic status,

\section{What is already known on this topic}

From 1970-2 to 1991-3 mortality in England and Wales declined in all social classes, though the gap in rates between higher and lower social classes increased

Estimates of change in health inequalities over time based on the gap between higher and lower classes do not take into account the effect of changes in the social class distribution of the population

\section{What this study adds}

$16 \%$ of the reduction in deaths between $1970-2$ and 1991-3 among men in England and Wales was attributable to increases in the proportion of men in higher social classes

Policies to reduce health inequalities should take into account their likely population impact and include efforts to shift the social class distribution upwards

and hence health, of the whole community and particularly in moving individuals up the socioeconomic distribution.

We are grateful to Allan Baker and Angela Donkin, Office for National Statistics, for supplying the mortality data and comments.

Contributors: RFH had the idea for this paper, PMcE performed the statistical analyses, and RE set the work in context. Each author wrote part of the paper, which evolved during repeated discussions between the three. RFH is guarantor.

Funding: None

Competing interests: None declared.

1 Engels F. The condition of the working-class in England. London: Lawrence and Wishart, 1984 (first published 1845).

2 MacIntyre S. The Black report and beyond: what are the issues? Soc Sci Med 1997;44:723-45.

3 Acheson D (chair). Independent inquiry into inequalities in health report. London: Stationery Office, 1998. www.official-documents.co.uk/ document/doh/ih/ih.htm (accessed 30 Mav 2002).

4 Drever F, Bunting J. Patterns and trends in male mortality. In: Drever F, Whitehead M, eds. Health inequalities: decennial supplement. London: Stationery Office, 1997 (DS series No 15).

5 Oliver A. On health inequality. J Public Health Medicine 2000;22:454-6.

6 Mackenbach JP, Kunst AE. Measuring the magnitude of socio-economic inequalities in health: an overview of available measures illustrated with two examples from Europe. Soc Sci Med 1997:44:757-71.

7 Heller RF, Dobson AJ. Disease impact number and population impact number: population perspectives to measures of risk and benefit. $B M J$ 2000;321:950-2

8 Heller RF, Page J. A population perspective to evidence based medicine: "evidence for population health." J Epidemiol Community Health 2002;56:45-7.

9 Blane B, Harding S, Rosato M. Does social mobility affect the size of the socio-economic mortality differential? Evidence from the ONS longitudinal study. JR Statist Soc S Ser A] 1999:162:59-70.

10 Townsend P, Davidson N, Whitehead M, eds. Inequalities in health:the Black report and the health divide. Harmondsworth: Penguin, 1988.

11 Raleigh VS, Kiri V. Life expectancy in England: variations and trends by gender, health authority and level of deprivation. J Epidemiol Community Health 1997;51:649-58.

12 National Health Inequalities Targets. www.doh.gov.uk/healthinequalities/ targets.pdf (accessed 30 May 2002).

13 Rose G. Sick individuals and sick populations. Int I Epidemiol $1985 ; 14: 32-8$

14 Rose G, Day S. The population mean predicts the number of deviant individuals. BMJ 1990;301:1031-4.

(Accepted 12 December 2001) 